\title{
Communication between road users and the influence of increased car automation
}

\author{
Christine Chaloupka ${ }^{a}$, Ralf Risser ${ }^{b}$ \\ ${ }^{a}$ Traffic Psychologist according to Austrian Law § 20 FSG-GV \\ ${ }^{b}$ Department of Psychology, Palacky University Olomouc, Czech Republic
}

\begin{abstract}
For a smooth, safe and comfortable cooperation of all actors in traffic good communication $^{1}$ is essential. In view of the progressing automation in traffic the impacts on communication have to be considered. This paper puts a special focus on car automation's impact on the communication between road users including interaction between highly automated vehicles and vulnerable road users (VRUs). The main research objective was to develop relevant assumptions concerning changing conditions of communication. To reach this objective, interviews with experts were carried out. The results show that various developments between the two poles - (1) implementation controlled by certain societal strategies or (2) implementation that just takes its course - are considered possible. Enhanced automation could lead to the decrease in the use of interpersonal communication while the use of digital communication gains the upper hand. Such a development, on the one hand is seen as a chance for the improvement of traffic safety and efficiency. On the other hand, interviewed experts also identify risks such as misunderstandings between VRUs and automated cars, with fatal outcomes, or reductions in traffic flow. This is expected to be the case especially during the transition phase where vehicles with different degrees of automation are on the road and where many road users outside vehicles move about, e.g. in densely inhabited areas, where $70 \%$ of the citizens in industrial countries live nowadays.
\end{abstract}

KEYWORDS: Communication in traffic, Automation, Unprotected roadusers

1 According to Watzlawick et al. (1967) and other communication specialists in this text the words Communication and Interaction will be used as synonyms.

\section{INTRODUCTION \& GOAL}

From 1987 to 1995 the Eureka PROMETHEUS Project (PROgraMme for a European Traffic of Highest Efficiency and Unprecedented Safety, 1987-1995), the largest Research and Development programme ever in the field of driver assistance (ADAS - Advanced Driver Assistance Systems) paving the way to automation of certain features of driving (Eureka 20; see Thrun 2010) defined the state of the art of such automation, then. The last two letters of the acronym PROMETHEUS stood for 'Unprecedented Safety'. Quite a lot of experts at that time doubted that many positive safety effects were to be expected, while positive safety effects where achieved in some cases (see Sternlund et al. 2017). The anticipated problems were similar to the problems nowadays: *) in regard to new technologies there usually exist only few accident data (e.g. Maki \& Sage 2018); *) nobody really knows how road users will interact with new systems; *) there is doubt whether traffic participants, mainly car drivers, will accept and use these innovations in the way that producers hope they will; *) it is unclear how interaction with the social environment (i.e. communication between road users respectively communication in the public space) will change.

No matter whether the character of changes in traffic and especially of driving that were expected at that time are the same or somewhat different from today, the fact remains that drivers will have to interact much more with technical systems, and in a much different way, which with high probability will affect communication with other road users. Today, drivers do not behave $100 \%$ according to the laws. Road users have learned that laws do not have to be followed fully and in any case. Behaviour is steered much by one's own perception and judgement and one's own assessment of what is safe, and by informal behavioural norms. Seen from this perspective, how will drivers react to new and much more intrusive sys- 


\section{Table 1: SAE levels of driving automation}

\begin{tabular}{l|l}
\hline * Level 0 & $\begin{array}{l}\text { No sustained vehicle control } \\
\text { * Level 1 }\end{array}$ \\
* Level 2 & $\begin{array}{l}\text { The driver and the automated system share control of the vehicle } \\
\text { driving and be prepared to intervene if necessary }\end{array}$ \\
* Level 3 & $\begin{array}{l}\text { The driver can safely turn their attention away from the driving tasks } \\
\text { * Level } 4\end{array}$ \\
* Level 5 & No human intervention is required at all. An example would be a robotic taxi. \\
\hline
\end{tabular}

tems that interfere with these tendencies? And how will communication between people on the road/in the public space change that until now has shaped the characteristics of traffic to a high degree? The last question, in our eyes, is in fact the central question, because traffic is clearly a network of interaction processes between people, that in the future will be invaded much more by "machine decisions".

Today, self-driving cars are, with high pressure from car industry, under development. Some have already reached the market. Industry and politicians expect fully automated cars not only to be driven on highways but in cities in a not so far future. The major benefits of such solutions are argued to be safety, convenience, fuel economy and lower emissions (Davila \& Nombela 2012; Rupp \& King 2010; Verberne et al. 2012). Taking these visions into consideration there is a high need to understand how citizens and users will - or could - react to the technology, and what possible benefits or difficulties or even dangers they perceive. This information is needed when designing the interfaces and interior of autonomous cars. Recent studies already emphasise that the driver's role will change - from steering to controlling the vehicle as well as watching the technical and social environment more intensively, to understanding and anticipating possible failures of the vehicle.

According to SAE J3016 ${ }^{2}$ (see table 1), automated systems may indeed be autonomous if they perform all of their functions independently and self-sufficiently, but if they depend on communication and/or cooperation with outside entities, they

2 Issued June 2018, SAE international's J3016 provides a common taxonomy and definitions for automated driving in order to simplify communication and facilitate collaboration within technical and policy domains. It defines more than a dozen key terms, including those italicized below, and provides full descriptions and examples for each level. should be considered cooperative rather than autonomous. EuroNCAP defines autonomous in "Autonomous Emergency Braking" ${ }^{3}$ as follows: "The system acts independently of the driver in order to avoid or mitigate the accident."

The formal SAE definition notes in particular what happens in the shift from SAE 2 to SAE 3: the human driver no longer has to monitor the environment. This is the final aspect of the "dynamic driving task" that is now passed over from the human to the automated system. At SAE 3, the human driver still has the responsibility to intervene when asked to do so by the automated system. At SAE 4 the human driver is relieved of that responsibility and at SAE 5 the automated system will never need to ask for an intervention. In fact, no driver needs to be inside the vehicle.

\section{Communication and interaction in traffic}

This leads to the core topic of this paper, namely the understanding of interaction and communication of road users and vehicles. It is the special nature of traffic that makes the communication in traffic different from the communication in "normal" life: the element of immediate social feedback that affects behaviour is missing. This is most notable for the group of VRUs (children and seniors in particular) who strongly rely on unambiguous communication with corresponding feedback. Human communication is both social behaviour and communicative acting. In contrast to digital communication human communication also fulfils the function of social learning as individuals learn from communicating with others. Especially during the transition phase, when there will be vehicles of different SAE levels (definition see

\footnotetext{
3 "Autonomous Emergency Braking - Euro NCAP". www.euroncap.com.
} 
above) together on the road, such an understanding and taking into consideration will be necessary to avoid problems between road users. ${ }^{4}$

The main question is how communication between different road users - especially unprotected ones and motor vehicle drivers - can happen, can be supported or will be obstructed, with more and more highly automated or autonomous vehicles in the traffic system. In this respect recently Färber (2016, citing Risser 1988) discussed especially the non-verbal and informal kinds of communication between different road users including pedestrians and cyclists, and possibilities of recognition by automated vehicles and vice versa. Moreover, it will be of interest how interaction and communication may develop during the already mentioned transition phase, where motor vehicles of different kind and extend of automation will meet each other. One big challenge is seen in people who are not sitting in a vehicle-pedestrians, cyclists - who would be interacting with a combination of manually-driven, semi-autonomous and fully autonomous vehicles in the near future.

\section{Goal}

The goal of the study this paper refers to was to develop assumptions concerning the expected impacts of car automation on the communication in traffic and thus in the public space (Füssl et al. 2017). This was done with the help of experts' interviews where expected or assumed impacts of (highly) automated and autonomous driving on communication in road traffic were reflected. Not least, the perspectives offered by the experts should help to identify important issues concerning relations between automation and communication between all road users that should be discussed, analysed further and, potentially, dealt with.

\section{COMMUNICATION IN TRAFFIC - HOW IT MAY DEVELOP}

Actually, for a smooth cooperation of all actors in traffic a good communication is essential (Risser \& Persson 1996). Accidents, or better, crashes - because they very often do not happen "by accident" - are, for

4 Merat \& Jamson (2009), "How do drivers behave in a highly automated car?" Institute for Transport Studies, University of Leeds. the most part, the results of problematic behaviour and interactions between different road users; only in rare cases it is technical defects that cause an accident (Risser et al. 1991). Already in the 80ies of the last century Hydén stresses the aspect of interpersonal interaction or communication in road traffic, focussing on road user behaviour as social behaviour (Hydén 1987). Road users are looked upon as members of a society behaving in a complex social context, and not so much as single individuals acting independently from the social environment. 'Communication' does not mean plain information (or omitting of information) and reaction to it. It also means deliberate neglecting of rules, thus offending others' rights and/or feelings, which might lead to dangerous situations; and it also means renouncing one's own right with the aim to be cooperative and/or polite (Risser 1985 and 1988). Communicating in traffic has many functions: it is necessary to recognize the implications for one's own behaviour in the behaviour of other road users; it is necessary to make oneself understood to the other road users; by giving signals, both safety and the fluency of traffic can be improved. But there can arise problems as well: Many of those signals are not explicitly defined by laws. Such nonofficial signals might be misunderstood. But some of the official signals are ambiguous as well. As a matter of fact, conflicts or errors can be caused by misleading or misunderstood communication.

That this topic is of big research interest is shown not only by the recent projects which are going on like that one of the Massachusetts Institute of Technology (Schmidt et al. 2019) who used an immersive virtual reality environment to explore the intricate social cues that underlie non-verbal communication involved in a pedestrian's crossing decision. They could show that pedestrians may use vehicle kinematics to deduce social intentions, and not merely as the state of a moving object. They were able to show that vehicles following intentionally atypical trajectories let to confusion and in some cases mistrust among participants, while more conventional trajectories did not. Pedestrians seemed to evaluate vehicle kinematics beyond a mere consideration of time to arrival, as was part of the results of a recent study done by Petzoldt et al. 2018, or Beggiato et al. 2017, as a social interaction from which they derive cues, going so far as to reflecting on the side of the driving entities perception of their own intentions. Vinkhuyzen and Cefkin (2016) present a study on translating observable social behaviour in road traf- 
fic into algorithms which can be read by automated cars, referring on the limitations of machines in recognizing the small differences in human signs or behaviour in general. But what to do if decisions and behaviour of pedestrians and cyclists towards (partly) automated vehicles are found to be different from their behaviour towards a vehicle driven by a human driver? The software developers cannot base their algorithms on what is known about current interactions and behaviour patterns (Vissers et al. 2016).

Studies like the one by Vinkhuyzen and Cefkin (2016) indicate that gestures like waving are common practice between drivers and pedestrians when negotiating right of way. Additionally, earlier research has concluded that a pedestrian's direct stare towards an oncoming driver invokes more compliant and yielding behaviour (Guéguen \& Jacob 2002, Guéguen, Meineri \& Eyssartier 2015). Šucha (2014b) determined from his study that interaction between a driver's choice of speed and a pedestrian's crossing decision is dependent on gaining "a maximum, whether it means time, safety, or comfort”. Šucha (2014a) came to the conclusion that a majority of pedestrians seek eye contact. The importance of eye contact was also investigated by Dey and Terken (2017) as well as Müller et al. (2016) and Lundgren et al. (2017). They all stated that road users establish eye contact to negotiate traffic situations.

The few studies that did examine the behaviour of pedestrians and cyclists in their interaction with automated vehicles, generally found that they were fairly cautious when interacting with an automated vehicle and not confident of its 'skills'. Furthermore, pedestrians and cyclists were found to appreciate messages and/or signals from the car indicating whether the car had detected them and what it intended to do. However, which exact messages need to be brought about and the method of communicating them are not yet settled and this requires further study (Vissers et al. 2016). Recently Schieben et al. (2019) expressed design considerations according to four categories of information: (1) information about vehicle driving mode; (2) information about AVs' manoeuvres; (3) information about AVs' perceptions of the environment; and (4) information about AVs' cooperation capabilities. They refer to authors like those mentioned above who already had investigated communication of pedestrians or cyclists with automated vehicles, as well as to Rasouli et al. (2017) or to Hagenzieker et al. (2016).

\section{METHOD AND PROCEDURE}

\section{The method Expert interview}

Expert interviews are a qualitative method. In contrast to quantitative approaches, such a method deals with any topic in an open-ended and holistic way. Expected developments, assumed relationship between facts, hypotheses concerning impacts of measures, etc. are mentioned and discussed. In this actual case, expert interviews serve the goal to sketch a picture of potential positive and negative consequences of automation concerning communication between people in the public space (Meuser \& Nagel 2002).

The future is nothing that can be connected to any scientific proof in advance. What is said in such interviews has the character of assumptions - probably intelligent and valid ones - but not of facts. It opens a field of possibilities. The probability of such possibilities coming true is not an issue, the goal is to identify as many plausible possibilities as possible. The principle of saturation prevails (Atteslander 2010). Qualitative surveys end when the researchers have the feeling that "nothing new“ is coming up any more in further interviews. It is up to quantitative procedures, later on, to find out how relevant certain assumptions, expectations and hypotheses really are. In other words, qualitative procedures help to detect/ identify phenomena (e.g., potential communication problems between road users), while quantitative ones will measure the distribution of such phenomena in the field/in the population (for instance see Cresswell \& Plano Clark 2007). In the frame of our expert interviews many relevant aspects were gathered that later on should be analysed with the help of additional qualitative studies - focus group interviews with road users and behaviour observations at selected spots in the road network - that should provide different perspectives and contribute to the list of potentially important issues concerning the relation between automation and communication. Quantitative studies were not foreseen in the frame of the project that constitutes the background for this paper (Füssl et al. 2017).

\section{Interviewees}

In total 15 experts from the areas research, technology and academia, and practitioners dealing with traffic infrastructure were interviewed, 12 males and 13 females of an age between 30 and 67 . They belonged to the disciplines psychology and sociology 
with a focus on mobility and transport, traffic planning and engineering, economical issues in connection with mobility and transport matters, and jurisdiction in this area. All of them were familiar with the concepts dealt with in the frame of our project. Their work places were the Austrian Department of Transport, technical universities and universities in Germany, the Czech Republic, Sweden and Austria, the Austrian automobile club ÖAMTC, car manufacturers in Germany and Sweden, the Belgian Traffic Research Board, and private research institutes.

\section{Procedure}

The interviews were partly carried out on the telephone and partly personally. The first contact was established by mail, in some cases followed up by a telephone call. The length of the interviews varied between half an hour and two hours. The interviews were recorded with the allowance of the interviewees, transcribed and analysed with the help of the thematic analysis procedure according to Froschauer \& Lueger (2003). In the frame of such a procedure, answers and/or answer elements are grouped to form categories foreseen when the questions were formulated. At the same time new categories or sub-categories may emerge and open up new perspectives whenever the interviewees touch aspects that have not been foreseen when preparing the interviews, thus producing new insight and understanding, and in this way opening up issues to be followed further-on.

The material to be analysed consists of sentences produced by the interviewees in their own wording. Therefore there is room for misunderstandings on the side of the interviewers. However, when open verbal material is concerned no good numeric approach concerning the reliability of one's understanding is possible. The way to achieve congruence is team discussion at several moments of the analysis, which consists in joint labelling of the statements of the experts as belonging to categories that either have been foreseen or that emerged from the collected materials. This strategy was strictly followed throughout the project work.

The transcriptions have been saved electronically by FACTUM Chaloupka and Risser and can be looked into in the case a replica of the study is carried out.

\section{Content and structures of questions}

To start with, the experts should be asked where they worked and in which respect, they dealt with traffic and - potentially - with automation, or autonomous driving. Then, the topic automated driving was discussed freely. "What comes to your mind when automated or autonomous driving is mentioned?" This should lead to ponderings and statements that would not be influenced by any assumptions that could be transported by more directed questions. The interview guideline would be present in the mind of the interviewer (of course supported by written notes in his/her hands), and open questions should be asked if the issues they would refer to had not been taken up by the interviewees themselves. After that they were asked what impacts on the social environment and on traffic they expected, with a focus on communication between road users and concerning the question how different groups of road users would be affected thereby. Another important question that we wanted to be answered was whether highly automated or autonomous vehicles should be denoted by some symbol or text on the vehicle. Towards the end of the interview we asked which cultural, social or ethical challenges would be generated by the introduction of highly automated or autonomous vehicles, a topic that frequently is discussed in recent literature (Gasser et al. 2015). Finally, the interviewees were given the possibility to add topics and areas that had not been taken up in the interview, so far, and that they considered relevant.

\section{FINDINGS}

The findings presented in the following reflect answers to questions concerning the future and what experts expect in the future. The experts answered all questions either by taking up the topics by themselves or as a response to an explicit question from our side when a certain topic had not been taken up earlier. The expert statements - what experts think of future developments - are below reported in a narrative way according to the categories that emerged from the material. They are not reproduced verbally but presented in a summarising way by the authors. No opinions or interpretations of the authors have been added. When discussing the expected changes in the traffic system we made use of the diamond model because it reflects relevant parts of the traffic system. To refer to such a structure will make it easier to take further steps both on the analysis side (standardised verbal data collections, pilot tests, demonstrators), later-on, and on 
the measures side, as far as statements are stringent enough in order to allow or to call for measures already at this stage.

\section{Transition phase}

The expectation was expressed that automation would change the traffic system fundamentally. Such change would provide both chances and risks. However, it was assumed that the most and the most severe problems would arise during the transition phase when vehicles with many different degrees of automation would be on the road. Many different assumptions were formulated about the duration of this phase, but the general assumption was that it would be a „long time“. Communication would be especially difficult during this phase, most of all for pedestrians and cyclists, i.e. for all road users that cannot be „automated“. Experts agreed that it will be possible to develop a fully automated system when only vehicles equipped with high tech are involved (e.g. on motorways), but things were supposed to be more difficult when persons outside the cars or without technical equipment would be involved. People would never interact with technical equipment like robots.

\section{Big differences between transport systems}

In some transportation sectors (rail, water-borne, air transport) systems are highly automated already, but a comparison with road transport is not fully possible because road transport is an open system where everybody can take part. There are limitations to equipping all elements in the system in such a way that automated driving would really be possible, at least not where there are people on the road outside vehicles, children, old persons, impaired persons, where the use of the public space is as heterogeneous as can be.

\section{Changes in the traffic system and, thus, in the public space}

The experts spontaneously mentioned elements belonging to all dimensions of the Diamond model of Risser (2004; see figure 1): * Society and its influence on the individual; * Infrastructure of the public space; * the characteristics and limitations of different transport/mobility modes; * and communication between road users. All those areas interact, and communication is one important part of the system that has to be dealt with intensively in the frame of further research.

\section{Communication in general}

The following points of view were expressed concerning communication: According to the experts' opinion communication between vehicles and nonmotorised traffic will be the most important area for discussion and research. Complexity in traffic will not decrease but will increase, is assumed. There will be vehicles with many different degrees of au-

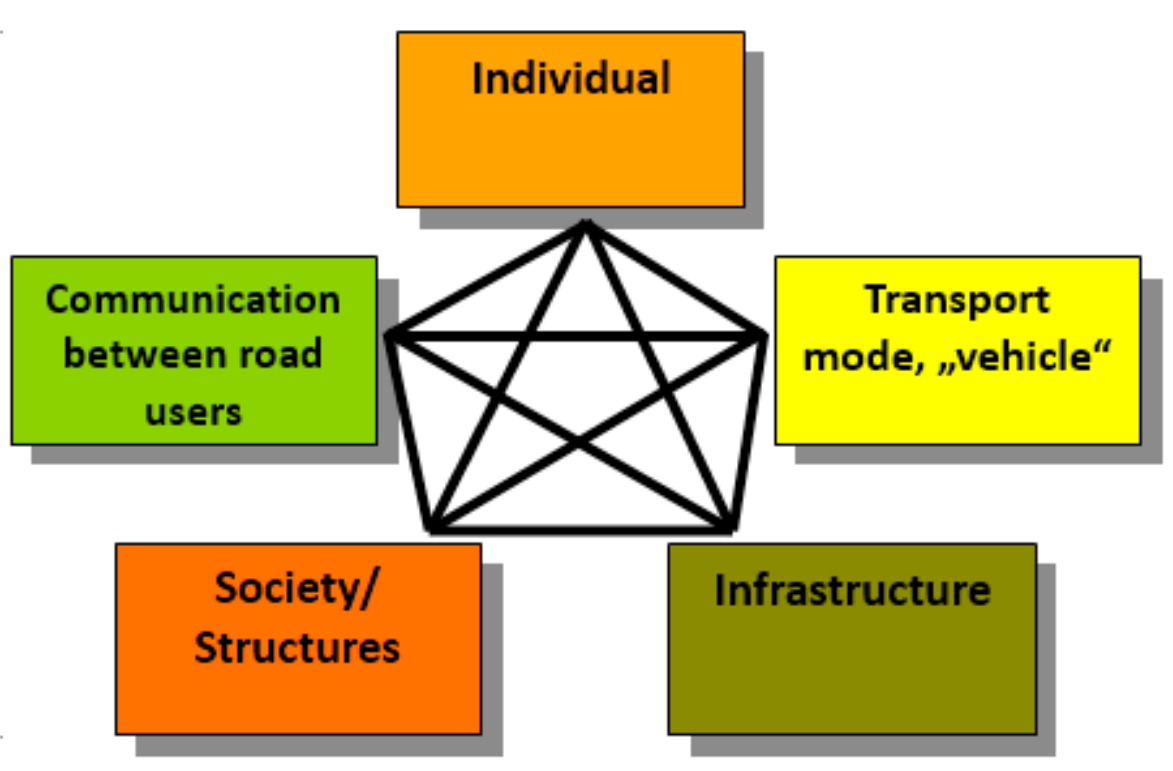

Figure 1: The diamond model of elements that influence road user behaviour (Source: Risser 2004) 
tomation on the road and they will mix with „fully non-automated" road users - pedestrians, cyclists, scooter-riders, e-board users, and others. Moreover, the public space is not only there for transport but also has other functions, which has to be considered, as well. To apply technical norms solely would certainly not work.

Generally, the interviewed experts assessed possible impacts of car automation on communication in traffic quite heterogeneously. While some of them guessed that increasing automation would hardly affect communication in traffic, others expected that person-to-person communication would gradually decrease. Concerning drivers, car-to-car communication would be enhanced by automation and replace person-to-person communication there.

\section{Interpersonal communication solves problems \& needs to be "protected“}

However, the experts pointed out that road users, especially those in mixed-mode areas, constantly have to cope with changing conditions and situations, many of which have to be tackled ad-hoc, usually with the help of interpersonal communication. Experts feel quite sure that such communication will not vanish, but how will it change under the influence of automation? How quickly will drivers be able to react in cases of emergency when they are asked to take over manually, not only in order to steer the vehicle but also to re-establish communication with the social environment? Will - possibly mandatory trainings be introduced that make drivers fit for such situations, similarly to other branches of transport? For instance it is stated that such training could be carried out on simulators.

\section{To consider non-motorised road users and the quality of the public space appropriately}

The opinion is expressed that industry is interested in introducing higher automated systems as quickly as possible and, thus, is prepared to work intensively with, e.g., the development and improvement of sensor systems to identify non-motorised road users. Automation is associated with improved traffic safety. But it is assumed that there is also awareness that subjective safety and sojourning quality of the public space, very important aspects of communication among road users, have to be tackled appropriately.

\section{Standardisation?}

Standardisation is seen as an important topic concerning communication. Will signals given by automated vehicles be well recognisable and understandable for everybody and all over the world, starting with Europe where car drivers have the possibility to drive their car in many different countries of different socialisation background, and already do so.

\section{How well can automated cars communicate?}

In spite of all statements that communication is important experts believe that communication among car drivers will decrease (and maybe lose relevance). The necessity for vehicle drivers to communicate actively is assumed to become less relevant as many communicative functions will be taken over by technical systems. For instance, to communicate that one renounces in one's right of way, or that the road user behind should/could overtake etc. will have to be done autonomously in the frame of car2car communication by highly automated or autonomous vehicles, in those cases where the driver is out of the loop (talking on the phone, reading the newspaper). Communication will become more anonymous, affecting social climate in the public space.

It is stated that there is already a lot of technical knowledge concerning car2car and car2infrastructure communication, also as far as programming is concerned. However, it is considered as most important to deal with interaction between vehicle drivers and persons outside vehicles. Some experts strongly underline that there is a lack of research and, thus, of knowledge, there. „Intelligent“ vehicles would have to learn to interpret movements, body language, mimics, signs by hands and face, etc. There are doubts how far such understanding can be programmed, especially in the frame of a two-way process going on in several steps where automated systems have to understand and to react appropriately. At this moment, only a few strongly standardised signals could be exchanged without high risk of being misunderstood. In any case, it is indispensable that non-motorised road users can rely fully on the rule-compliance of highly automated/autonomous vehicles.

\section{Traffic safety}

In fact, respecting speed limits, keeping safe distance to the car in front, and more generally compliance, 
with the rules are expected to improve in connection with automation, on the one hand. On the other hand, safety problems could arise due to the fact that interpersonal communication as a last resort that has the potential to deal with unclear situations - that cannot be standardised beforehand - is given less weight and less space in the frame of a highly automated traffic system. In a mixed system, average speed would certainly go down, due to the necessarily defensive programming of such highly automated cars. But in connection with this, the question is how to consider informal rules appropriately, which will be especially relevant in the transition phase - or which probably always will be relevant when there are people outside cars on the road. Unexpected behaviour at traffic lights, unexpected slowing down for pedestrians crossing mid-block and many other comparable situations will, or could, cause troubles in the interaction with vehicles with lower automation where drivers have to react who have internalised ${ }^{5}$ informal norms for many of those situations. Thus, informal norms that actually are the outcome of continuous communication processes would be one important stumbling block concerning future traffic safety, in any case during the transition phase and in areas where there are (many) non-motorised road users.

In general, the interviewed experts and road users see automated driving as a great chance for improvements in traffic safety, although, at the same time, they expect certain risks. Especially the phase of mixed traffic with different degrees of automation present is considered critical. As for the improvement of the subjective feeling of safety of the VRUs the respondents deem necessary that the possibility of receiving a signal from the car (the driver?) about the next car move is given, respectively that the cars/ (drivers) "read" the pedestrian signals correctly.

The major concern is that wearing transmitting devices will possibly become mandatory for cyclists and pedestrians. The labelling of automated vehicles is another issue that was mentioned as relevant with regard to traffic safety. Particular issues - such as standardisation and deployment of automated vehicles, what kind of information is transmitted and how it will be transmitted (auditory or visual) - need to be clarified. Another issue was whether standard-

5 Internalisation: The action of accepting or absorbing an idea, opinion, belief, etc. so that it becomes part of your character" (Cambridge Dictionary) i.e. it is not reflected any more. ised programming of automated vehicles is realistic and feasible, how well car manufacturers will cooperate, and how strongly law makers will act in this respect.

\section{Efficiency}

The opinion is expressed that efficiency of road traffic in a highly automated system could increase on motorways. In mixed traffic, i.e. where there are (many) non-motorised road users, efficiency could suffer due to defensive programming (that is absolutely necessary) and due to a probable lack of flexibility in unclear or chaotic situations. Nowadays, nobody knows how interaction „between persons and machines“ will work in such situations. Research is going on, but there seems to be the belief that appropriate programming of such situations will only be possible in the very long run. In cities, thus, efficiency would suffer, at least seen from the perspective that we have today. For instance, how would you deal with a thin but never-ending stream of pedestrians crossing an inner-city street. Either, the highly automated car would stand there forever, or it would be necessary to introduce traffic lights, which does not solve the problem mid-block, however.

Summing up, traffic efficiency could be increased in "closed" systems like highways. However, in areas where car traffic meets other road users (pedestrians and cyclists) and the road space has to be shared, the impact of automated driving on traffic efficiency has been assessed as difficult to predict.

\section{Impact on different road user groups}

In many highway codes there is usually a paragraph that as a road user one has the right to take for granted that the other road users abide by the rules. However, this is not valid vice versa. According to the experts, and as a matter of fact, children, (very) old people, cognitively impaired people (e.g. due to dementia) and others (e.g. drunk pedestrians) are exempted from this principle (at least in the Austrian Highway code). In other words, other road users cannot take it for granted that they will abide by the rules. It will be especially difficult to „automatize“ communication processes between these groups and intelligent cars, and the problem will not diminish as far as older persons are concerned. Society is ageing and, thus, portions of people with dementia or with other cognitive or sensory impairments will increase. 


\section{Did any intelligent systems so far improve communication among road users?}

Not very many ITS or ADAS came to the minds of the experts when asked whether they had contributed to improving communication in traffic. Positive examples where lane-changing-assistance systems or blind-angle-scanning systems. Both of them would allow drivers to perceive other road users timely and thus help to make interaction with those others safer.

\section{Should highly automated or autonomous vehicles be denoted with words or symbols?}

Experts in favour of denoting argued that highly automated or autonomous vehicles would behave differently from vehicles that people were more used to and thus have, as already mentioned, internalised spontaneous behaviour to cooperate with. Denoting would raise awareness of this fact and other road users could adjust their behaviour in the frame of communication processes. They considered this especially important during the transition phase. For instance, barely visible sings with the hand or slight changes of the body posture that indicate that a pedestrian renounces his right of way will hardly be recognised clearly by automated systems. Programming has to be very defensive for these cases, because misunderstandings leading to erroneous assumptions that the pedestrian would renounce his/her right of way could be fatal. Therefore, one would rather expect that the cars "wait" in spite of being invited to drive on, possibly causing confusion on the part of the pedestrian. But if pedestrians can see right away that they are interacting with an autonomous or highly automated car it will be easier for them to adjust.

Others argue that denoting could lead to disadvantages. There could be the risk that other road users "test" those highly automated vehicles; e.g., "does it really stop"? Or that drivers of cars with lower automation drive more aggressively because the denoted ones are programmed to drive defensively.

If denotation of highly automated or autonomous cars was introduced, then it should be standardised and internationally recognisable and valid. Denotation should be as clear and unequivocal as the labelling of, e.g., taxis and driving school cars. Moreover, if those cars should be recognisable then there should also be some auditory information so that vision-impaired persons can recognise them. Not least, a digital labelling was recommended if it was decided to denote high-tech cars, so that other vehicles could receive information via this channel (of course, these other vehicles should have a receiver to catch such signals).

\section{Cultural differences, social consequences and ethical challenges}

Interestingly, none of the experts did see any challenges connected to cultural differences in different countries or regions in spite of the fact that we perceive differences in communication in different countries. Everywhere, highly automated vehicles would be programmed to respect all official rules, and everywhere "non-automated" road users would have to adjust to this. Of course, it will be important to thoroughly consider existing laws/rules when programming.

Concerning social consequences, one interesting comment was that drivers of highly automated cars or users of autonomous vehicles would "unlearn" to communicate in traffic, or in the public space more generally, with consequences that could not be predicted.

Ethical challenges where discussed following the scheme "would you let the system kill one person in order to save five others"? This is a moral dilemma of the programmers, respectively of their bosses and no answer can be given at this moment. A broad and comprehensive discussion about ethical issues was seen as essential for the respondents, even before the deployment of the automated vehicles worldwide.

Table 2 below points out and sums up how experts expect traffic to change in connection with increasing automation. Impacts on communication and, consequently, on traffic safety and efficiency are summarized.

\section{DISCUSSION AND CONCLUSIONS}

To start with, it should be added here that no scientific proof can be provided immediately concerning the relevance of the expectations that are expressed, as they deal with the future and future possibilities. The experts predict both improvements and problems concerning future traffic under the influence of increasing automation. The future will show which predictions come true but, as well, further research will shed more light on developments that may be expected. One may hope (expect?) that societies go for a serious evaluation of the effects of automation at an 
Table 2: Expected changes in the traffic system/in the public space; potentials and challenges

\begin{tabular}{|c|c|c|}
\hline & Potentials & Challenges \\
\hline Communication & 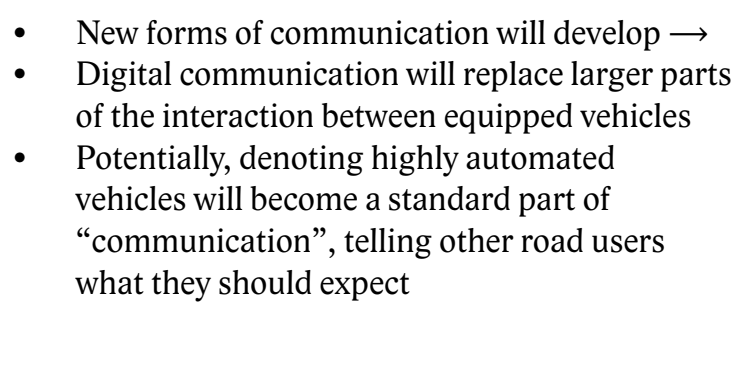 & $\begin{array}{l}\text { Loss of flexibility in interaction processes } \\
\text { due to the reduced role of interpersonal } \\
\text { communication } \\
\text { Communication becomes more anonymous, } \\
\text { social climate may deteriorate } \\
\text { Certain groups - children, impaired persons, } \\
\text { very old persons - may have difficulties to cope } \\
\text { Lack of standardisation of new signs and } \\
\text { symbols could cause misunderstandings }\end{array}$ \\
\hline Traffic safety & $\begin{array}{l}\text { Potentially the number of accidents is reduced due to } \\
\text { - } \quad \text { Abiding by the rules of highly automated } \\
\text { vehicles } \\
\text { - } \quad \text { Lower average speeds in mixed-mode areas }\end{array}$ & $\begin{array}{l}\text { - Increased risk of accidents during the } \\
\text { transition phase when vehicles of many } \\
\text { different types of automation are on the road } \\
\text { Reduced subjective safety of old people, } \\
\text { children (their parents), etc. due to a new and } \\
\text { unknown complexity of the communication } \\
\text { processes } \\
\text { Machines have no intuition, not all unexpected } \\
\text { events can be foreseen and programmed } \\
\text { Drivers un-learn manual driving due to a lack } \\
\text { of exercise } \\
\text { More risky behaviour of VRUs because they } \\
\text { know that highly automated vehicles will drive } \\
\text { defensively }\end{array}$ \\
\hline $\begin{array}{l}\text { Efficiency- } \\
\text { capacity- }\end{array}$ & $\begin{array}{l}\text { - Increased/improved capacity of motorways due } \\
\text { to more homogeneous speeds in the long run } \\
\text { Increased efficiency due to a reduction of } \\
\text { accidents on motorways and ... } \\
\text {-... due to the rule-abiding behaviour of highly } \\
\text { automated vehicles }\end{array}$ & $\begin{array}{l}\text { Increased portion of motor vehicles on the road } \\
\text { if everybody can drive or can be transported } \\
\text { and if cars could even drive alone in the highest } \\
\text { stadium of automation, leading to a drastic } \\
\text { change of the social character of the public } \\
\text { space } \\
\text { Decreased efficiency in mixed-mode areas }\end{array}$ \\
\hline Society & $\begin{array}{l}\text { - If high automation does not work well in } \\
\text { densely inhabited the portions of motor- } \\
\text { vehicles there might go down, making those } \\
\text { areas more attractive }\end{array}$ & $\begin{array}{l}\text { Drivers will un-learn to communicate } \\
\text { (communication does not work so well today } \\
\text { but this could become even worse), causing } \\
\text { negative impact on the social climate in the } \\
\text { public space }\end{array}$ \\
\hline
\end{tabular}

early stage, preventing negative developments from the beginning. Transport policy could accompany the introduction of automated vehicles in such a way that negative outcomes are avoided. Goals of such policy would first of all be to avoid problems in densely inhabited areas - that is where most of the citizens in the industrial countries live nowadays - with the help of research and professional know-how, by focussing especially on the safety and comfort of residents and vulnerable road users.

The findings are to some extent controversial: Some authors (see Davila \& Nombela 2012; Rupp \& King 2010; Verberne et al. 2012) expect major benefits concerning safety, convenience, fuel economy and emissions, and part of the experts interviewed in the present study agree. But another part pointed out that considerable problems for VRUs could arise, and that counteracting such problems from the beginning was essential: It was repeatedly stated that lack of understanding of behaviour of automated cars, respectively of new types of processes generally in connection with automation could lead to misunderstandings and both, objective and subjective safety problems of VRUs (see Vissers et al. 2016). Would searching of eye-contact help? But what if there would be a driver out of the loop or no car driver at all? Would the automated car recognize and "understand" this searching activity? Appropriate (easily available, understandable, interesting) information for the public concerning new developments in traffic 
would be essential, thus. Road users should be well informed and familiar with the technical possibilities of highly and fully automated cars. Furthermore, drivers should be able to handle automated cars expertly and safely (see here the already mentioned approach of Schieben et al 2019).

Low-speed areas - i.e. those areas where there is a mix of modes - should predominantly serve the pedestrians and cyclists, negotiation should determine the processes and thus maintain flexibility provided by interpersonal communication. Otherwise, the public space would become an area for robots only. In the long run, automated vehicles should be able to decode human gestures and give unambiguous feedback for other road users to inform them of the next moves of the car. The VRUs are free to carry receivers/transmitters (for "mode-to-mode" communication), although even without such devices they should be reliably detected by the automated vehicles. Still, it is assumed that fully automated driving will not be possible in low-speed areas (under $30 \mathrm{~km} / \mathrm{h}$ - which some consider the future at an increasing number of places in an increasing number of cities). Policy makers should also see to it that all signals emitted by the cars and the programming of all driving manoeuvres will be standardized across Europe for all manufacturers. It appears as logical, in this connection, that there will be clear regulations as to which information automated vehicles must send to VRUs, and how.

In sum, the hope is that it will be seen to it that automated vehicles and VRUs are able to communicate, i.e. that inputs and outputs can be decoded and understood on both sides. At the same time, automated vehicles will have to act defensively and there is the potential that VRUs will dominate and dictate the communication in low speed areas. Moreover, automated vehicles can only act and react according to their coding. There will certainly be (severe) short comings in this coding in the beginning. Should automated vehicles play a greater role in mixed mode areas in the future, this coding needs to be developed further to cover as many potential expressions of human communication in traffic, i.e. in the public space, as possible (see Schieben at al 2019, Vinkhuyzen and Cefkin 2016). Especially Färber (2016) showed in detail how complex these expressions are and that they also reflect relational aspects and do not only serve the exchange of factual information. Among others, Petzold et al. (2018) clearly found that pedestrians interpret what automated vehicle do as part of a dialogue with mutual understanding. It will be interest- ing to see whether programmers will be able to enable automated cars to live up to the expectation that automated cars can understand one's intention. The quality of the public space will certainly be affected by the developments in this respect. Social climate in the cities will change. It is questionable whether seeing to it that vehicles understand the intentions of non-motorised persons and forward correct information to the other road users will suffice. The hope is that societies - i.e. decision makers and parliaments - will see to it that the developments lead to an improvement of the quality of life of citizens, and not the contrary.

\section{Short comings and limitations}

This paper reports the results of interviews with experts with respect to their expectations concerning future impacts of automation on the communication among road users, especially among (highly) automated cars and vulnerable road users. The results of such a study are per se not telling much about reality, only about a potential future reality. Without follow-up analyses of a more quantitative and objectively empirical character their value cannot be deployed. However, they can give hints to what future research, and maybe what measures, will be necessary and useful, even with the scope to prevent non-wished-for developments.

\section{REFERENCES}

Atteslander, P., (2010). Methoden der empirischen Sozialforschung, Berlin: Erich Schmidt Verlag.

Beggiato, M., Witzlack, C., Springer, S., \& Krems, J., (2017). The Right Moment for Braking as Informal Communication Signal Between Automated Vehicles and Pedestrians in Crossing Situations. In International Conference on Applied Human Factors and Ergonomics (pp. 1072 - 1081). Springer, Cham.

Creswell, J.W. \& Plano Clark, V.L., (2007). Designing and conducting mixed methods research, Wiley Online Library.

Davila, A. \& Nombela, M., (2012). Platooning - Safe and EcoFriendly Mobility. In SAE 2012 World Congress \& Exhibition. Detroit, Michigan: SAE International.

Dey, D. \& Terken, J., (2017). Pedestrian Interaction with Vehicles: Roles of Explicit and Implicit Communication. https://dl.acm.org/citation.cfm?doid=3122986.3123009)

EUREKA Project E!45 PROMETHEUS. EUREKA Website. Retrieved 2019-05-22.

Färber, B., (2016). Communication and Communication Problems Between Autonomous Vehicles and Human Drivers, in: Maurer M., Gerdes J., Ch., Lenz B., \& Winner H., 2016 
Autonomous Driving. Technical. Legal and Social Aspects., Springer Berlin Heidelberg https://link.springer.com/chapter/10.1007/978-3-662-48847-8 7

Froschauer, U. \& Lueger, M., (2003). Das qualitative Interview: Zur Praxis interpretativer Analyse sozialer Systeme, Vienna: Facultas.

Füssl, E., Ausserer, K., Risser, R. \& Bahr, P., (2017). Kommunikation zwischen VerkehrsteilnehmerInnen: Einfluss zunehmender Fahrzeugautomatisierung, Vienna: FACTUM OG.

Gasser, T. M., Seeck, A. \& Smith, B. W., (2015). Rahmenbedingungen für die Fahrerassistenzentwicklung. In: Handbuch Fahrerassistenzsysteme. Grundlagen, Komponenten und Systeme für aktive Sicherheit und Komfort. Springer Verlag.

Guéguen, N. and Jacob, C. (2002). Direct Look Versus Evasive Glance and Compliance With a Request. J. Soc. Psychol. 142, 3 (2002), 393-396. DOI:https://doi. org/10.1080/00224540209603907

Guéguen, N., Meiner,i S., and Eyssartier, Ch., (2015). A pedestrian's stare and drivers' stopping behavior: A field experiment at the pedestrian crossing. Saf. Sci. 75 (2015), 87-89. DOI:https://doi.org/10.1016/j.ssci.2015.01.018

Hagenzieker, M.P., van der Kint L., Vissers, L.K., van Schagen I., de Bruin J., van Gent P., \& Commandeur, J., (2016). Interactions between cyclists and automated vehicles: results of a photo experiment. In: Proceedings of the 5th international cycling safety conference, Bologna

Hydén, Ch., (1987). The development of a method for traffic safety evaluation: The Swedish traffic conflict technique. Lund Institute of Technology, Dep. of Traffic Planning and Engineering, University of Lund.

Lundgren, V. M. et al., (2017). Will There Be New Communication Needs When Introducing Automated Vehicles to the Urban Context?. In: Stanton, N., Landry, S., Di Bucchianico, G., \& Vallicelli, A. (eds) Advances in Human Aspects of Transportation. Advances in Intelligent Systems and Computing, vol 484. Springer, Cham

Maki, S. \& Sage, A., (2018). Self-driving Uber car kills Arizona Woman crossing street. Reuters, Retrieved 14 April 2019.

Merat, N. \& Jamson, A. H., (2009). How do drivers behave in a highly automated car? Proceedings of the 5th International Driving Symposium on Human Factors in Driver Assessment, Training and Vehicle Design (pp. 514-521.). Big Sky MT.

Meuser, M. \& Nagel, U., (2002). Experteninterviews - vielfach erprobt, wenig bedacht. Ein Beitrag zur qualitativen Methodendiskussion. In: Bogner, A., Littig, B., Menz, W. (Hg.): Das Experteninterview. Theorie, Methode, Anwendung. Opladen, pp 71-94.

Müller, L., Risto, M., \& Emmenegger, C., (2016). The social behaviour of autonomous vehicles. In Proceedings of the 2016 ACM International Joint Conference on Pervasive and Ubiquitous Computing Adjunct - UbiComp'16 (pp. 686-689). New York, NY, USA: ACM Press. DOI: 10.1145/2968219.2968561

Rasouli, A., Kotseruba, I., \& Tsotsos J.K., (2017). Agreeing to cross: How drivers and pedestrians communicate. In: Proceedings of the 2017 IEEE intelligent vehicles symposium (IV), pp 264-269
Risser, R., (1985). Behaviour in traffic-conflict situations. Accident analysis and prevention 17/2 pp 179-197.

Risser, R., (1988). Kommunikation und Kultur des Straßenverkehrs. Habilitationsschrift an der Universität Wien: Literas Verlag.

Risser, R., (2004). Philosophy of Traffic Calming, in: The Asian Journal, Journal of Transport and Infrastructure 11/1, pp 1.

Risser, R., Zuzan, W.D., Tamme, W., Steinbauer, J. \& Kaba, A., (1991). Handbuch zur Erhebung von Verkehrskonflikten mit Anleitungen zur Beobachterschulung. Vienna: Literas.

Risser, R. \& Persson, H., (1996). Kommunikation im Straßenverkehr - Ein Grundlagenpapier, Lund Institute of Technology and Vienna: Factum OG .

Rupp, J. D. \& King, A. G., (2010). Autonomous Driving A Practical Roadmap. In SAE Technical Paper Series 2010-012335. Warrendale, PA, USA: SAE International.

SAE 2014, SAE International J3016. Levels of driving automation are defined in new SAE international standard J3016. www.sae.org/autodrive.

Schieben, A., Wilbrink, M., Kettwich, C. et al., (2019). Designing the interaction of automated vehicles with other traffic participants: design considerations based on human needs and expectations. Cogn Tech Work (2019) 21: 69. https://doi. org/10.1007/s10111-018-0521-z

Schmidt, H., Terwilliger, J., AlAdawy, T., \& Fridman, L., (2019). Hacking nonverbal communication between pedestrians and vehicles in virtual reality, Massachusettes Institute of Technology; https://arxiv.org/pdf/1904.01931 derived 30.05.2019

Sternlund, S., Strandroth, J., Rizzi, M., Lie, A. \& Tingvall, C., (2017). The effectiveness of lane departure warning systems-A reduction in real-world passenger car injury crashes, Traffic Injury Prevention, 18:2, 225-229, DOI: $\underline{10.1080 / 15389588.2016 .1230672}$

Šucha, M., (2014a). Pedestrians and drivers: their encounters at zebra crossings. Fit to drive 8th Int. Traffic Expert Congress, May (2014).

Šucha, M., (2014b). Road users' strategies and communication: driver-pedestrian interaction. In Transport Research Arena (TRA) 2014 Proceedings. Paris.

Thrun, S., (2010). Towards Robotic Cars. Communications of the ACM, 53 (4), pp 99-106.

Verberne, F. M. F., Ham, J. \& Midden, C. J. H., (2012). Trust in Smart Systems: Sharing Driving Goals and Giving Information to Increase Trustworthiness and Acceptability of Smart Systems in Cars. Human Factors: The Journal of the Human Factors and Ergonomics Society, 54(5), 799-810.

Vinkhuyzen, E. \& Cefkin, M. , (2016). Developing Socially Acceptable Autonomous Vehicles, Proc. Ethnogr. Prax. Ind. Conf.(2016), 423-435. https://doi.org/10.1111/15598918.2016.01108

Vissers, L. K., van der Kint, L., van Schagen, I. \& Hagenzieker, M.P., (2016). Safe interaction between cyclists, pedestrians and automated vehicles: what do we know and what do we need to know? Report of the SWOV Institute for Road Safety Research, 
The Hague. https://www.swov.nl/publicatie/safe-interactionbetween-cyclists-pedestrians-and-automated-vehicles.

Watzlawick, P., Beavin, J.B. \& Jackson, D.D., (1967). Pragmatics of Human Communication: A Study of Interactional Patterns, Pathologies and Paradoxes, W. W. Norton \& Company. 